\title{
Multiple Chronic Conditions Among US Adults Who Visited Physician Offices: Data From the National Ambulatory Medical Care Survey, 2009
}

\author{
Jill Jacobsen Ashman, PhD; Vladislav Beresovsky, PhD \\ Suggested citation for this article: Ashman J], Beresovsky V. Multiple Chronic Conditions Among US Adults Who Visited \\ Physician Offices: Data From the National Ambulatory Medical Care Survey, 2009. Prev Chronic Dis 2013;10:120308. \\ DOI: http://dx.doi.org/10.5888/pcd10.120308通.
}

PEER REVIEWED

\begin{abstract}
Most research on adults with chronic conditions focuses on a single disease or condition, such as hypertension or diabetes, rather than on multiple chronic conditions (MCC). Our study's objective was to compare physician office visits by adults with MCC with visits by adults without MCC, by selected patient demographic characteristics. We also identified the most prevalent dyads and triads of chronic conditions among these patients. We used the National Ambulatory Medical Care Survey, a nationally representative survey of office visits to nonfederal physicians and used 13 of the 20 conditions defined by the National Strategic Framework on Multiple Chronic Conditions. Descriptive estimates were generated and significant differences were tested.
\end{abstract}

In 2009, an estimated 326 million physician office visits, were made by adults aged 18 years or older with MCC representing $37.6 \%$ of all medical office visits by adults. Hypertension was the most prevalent chronic condition that appeared in the top $5 \mathrm{MCC}$ dyads and triads, by sex and age groups. The number of visits by patients with MCC increased with age and was greater for men than for women and for adults with public rather than private insurance. Physicians were more likely to prescribe medications at office visits made by patients with MCC. Physician office visits by adults with MCC were not evenly distributed by demographic characteristics.

\section{Introduction}

Most research on adults with chronic conditions focuses on a single disease or condition, such as hypertension or diabetes; little attention is focused on multiple chronic conditions (MCC) in 1 patient. This study compares, by selected demographic characteristics, physician office visits by adults with MCC with visits by adults without MCC. We also present findings on the most common MCC dyads and triads.

\section{Analysis}

\section{Data source}

The National Ambulatory Medical Care Survey (NAMCS) is a nationally representative annual survey of patient office visits to nonfederal physicians. The NAMCS sampling frame includes all physicians in the American Medical Association and American Osteopathic Association master files, excluding anesthesiologists, radiologists, and pathologists. The 2009 NAMCS (1) used a multistage probability design and included 1,293 physicians who completed patient record forms. The unweighted response rate was $62.1 \%$, and the weighted response rate was $62.4 \%$ (1). This study included the 28,693 patient record forms that physicians completed for visits by patients 18 or older for NAMCS 2009. We excluded visits by patients under age 18. Patient information recorded during the visit was abstracted from medical records and entered onto the patient record forms. 
Estimates are based on sample data weighted to produce national estimates and include standard errors. Estimates are not presented if they are based on fewer than 30 cases in the sample data. Estimates based on 30 or more cases include an explanation if the relative standard error of the estimate exceeds $30 \%$.

\section{Definitions}

The US Department of Health and Human Services (HHS) Interagency Workgroup on Multiple Chronic Diseases (IWMCD) created a list of 20 chronic conditions common in the United States (2). NAMCS includes check boxes for 13 of these conditions: arthritis, asthma, cancer, chronic kidney disease, chronic obstructive pulmonary disease, congestive heart failure, coronary artery disease, depression, diabetes, hyperlipidemia, hypertension, osteoporosis, and stroke. A checked box for any of these conditions on NAMCS indicates that the medical record contains documentation that the patient was given a diagnosis of the condition at some point, not necessarily during the current visit. The remaining 7 conditions on the HHS-IWMCD list - autism spectrum disease, cardiac arrhythmias, dementia, HIV, hepatitis, schizophrenia, and substance abuse disorders - do not have check boxes on NAMCS. A separate NAMCS question collects the primary diagnosis (as well as 2 additional diagnoses) for the current visit. If 1 of the 7 conditions that are not on the checklist show up in the diagnosis question, we could have included that condition in the count of chronic conditions that we used for this study. However, if the same patient had visited the doctor for a condition or ailment unrelated to 1 of the 7 conditions without check boxes, we would have no way of identifying that chronic condition and could not include it in our count. Because we cannot accurately count the number of visits that patients with these 7 conditions made, we excluded those 7 conditions from our study. We focus exclusively on the 13 conditions with check boxes on NAMCS.

We summed conditions and grouped them into 3 categories (o or 1, 2 or 3 , and $\geq 4$ ), with MCC defined as 2 or more chronic conditions per visit to a physician. We created dyads by summing yes responses for every combination of 2 chronic conditions. We identified the most common dyads by patients with at least 2 of the 13 chronic conditions $(\mathrm{n}=$ 9,871 unweighted visits). We created triads by summing yes responses for every combination of 3 chronic conditions. We identified the most common triads by patients with at least 3 of the 13 chronic conditions ( $n=4,986$ unweighted visits). In 2009, race data were missing from NAMCS for $24.4 \%$ of physician office visits, and ethnicity data were missing for $25.7 \%$. NAMCS staff used model-based single imputation to create imputed race/ethnicity variables. Race/ethnicity imputation is restricted to 3 categories (white, black, and other) on the basis of research by a NAMCS internal work group that identified quality concerns with imputed estimates for race/ethnicity categories other than white and black. Extensive research was conducted on the imputation method and is described in more detail elsewhere (1). We combined the imputed NAMCS race and ethnicity variables to form $4 \mathrm{racial} /$ ethnic groups: nonHispanic white, non-Hispanic black, non-Hispanic other, and Hispanic persons of any race. "Non-Hispanic other" includes Asians, Native Hawaiian/Pacific Islanders, American Indian/Alaska Natives, and persons of more than 1 race.

NAMCS collects all expected sources of payment listed in the medical chart. We combined these variables into 4 mutually exclusive insurance groups: public insurance (all visits with Medicare or Medicaid/Children's Health Insurance Program [CHIP]) as the expected source(s) of payment); private insurance (all visits paid for by private insurance, provided the public insurance box was not also checked); and no insurance (visits with self-pay or "no charge/charity" checked, provided that public or private insurance was not also checked); and other (the remaining visits not classified into 1 of the first 3 groups, [visits paid for by Workers' Compensation and other types of insurance, and unknown: $2.4 \%$ of all visits]).

NAMCS collects up to 8 medications that are documented in the medical chart as having been prescribed or provided during the visit. NAMCS includes prescription medications, over-the-counter preparations, immunizations, and desensitizing agents, and medications can be new or continued. Because NAMCS limits the total number of medications that can be recorded per visit to 8 , a record of 8 medications indicates that the patient has been prescribed at least 8 , but the number could actually be higher. Only $9 \%$ of all physician office visits were made by patients with 8 medications, so limiting medications to 8 does not affect a large percentage of total visits (3).

\section{Statistical analysis}

Differences among subgroups were evaluated with 2-tailed $t$ tests by using $P<.05$ as the level of significance. A weighted least squares regression analysis was used to evaluate the significance of trends. All comparisons reported in this article were statistically significant.

\section{Results}

\section{Physician office visits by sociodemographic group}

In 2009 adult patients made an estimated 867,783,000 physician office visits (Table 1). Patients with multiple chronic conditions made an estimated 326 million physician office visits representing $37.6 \%$ of all visits made by adults (data not shown). The majority of all visits were made by non-Hispanic white adults. Adult visits were distributed evenly by age. An estimated $61.7 \%$ of visits were made by women. Approximately half of all visits were made by patients with 
private insurance and about a third was made by those with public insurance (Table 1). However, there was great variation in insurance status by age. Only $17 \%$ and 19\% respectively of visits made by those aged 18 to 44 and aged 45 to 64 were made by patients with public insurance, whereas $80 \%$ of visits made by those aged 65 and older were made by patients with public insurance (data not shown). Private insurance showed the inverse, with $65 \%$ and $71 \%$ respectively of visits by those aged 18 to 44 and aged 45 to 64 being made by patients with private insurance, whereas only $17 \%$ of visits by those aged 65 or older were made by patients with private insurance (data not shown).

\section{Physician office visits by patients with MCC by sex, age and race}

In 2009, 29.2\% of physician office visits were made by adult patients with 2 or 3 chronic conditions, and $8.4 \%$ of visits were made by patients with 4 or more MCC (Table 2). Visits made by younger patients were less likely to be made by patients with MCC (9.3\% of visits by adults aged 18 to 44 years had 2 to 3 chronic conditions compared with $32.4 \%$ of visits by adults aged 45 to 64 and $44.4 \%$ of visits by patients aged 65 or older). This increasing trend by age for 2 or 3 chronic conditions was seen for visits by men and women and for visits by non-Hispanic white, non-Hispanic black and Hispanic patients. The increasing trend by age for patients with 4 or more chronic conditions was also seen for visits by both sexes and visits by all racial/ethnic groups for which we had reliable estimates.

Visits by men (32.6\%) were more likely than visits by women (27.0\%) to be made by patients with 2 or 3 chronic conditions, and this trend persisted for visits by non-Hispanic whites, non-Hispanic blacks, and Hispanics. For visits by patients younger than 65, visits by men were more likely than visits by women to be made by patients with 2 or 3 chronic conditions. This sex difference persisted for visits by non-Hispanic blacks and Hispanics aged 18 to 44 , and for visits by non-Hispanic whites and Hispanics aged 45 to 64 . Visits by men and women aged 65 or older were equally likely to be made by patients with MCC, regardless of race/ethnicity.

\section{Physician office visits by patients with MCC by sex, age, and insurance}

We found significant differences among visits made by patients with insurance (public, private, or other) and those with no insurance (Table 3). Visits by patients with private insurance (23.7\%), other insurance (20.2\%), or no insurance (16.0\%) were less likely to be made by patients with 2 to 3 chronic conditions than were visits by patients with public insurance (39.5\%). This difference by insurance status persisted for visits made by patients with 4 or more chronic conditions.

A greater proportion of visits by patients aged 65 and older with public rather than private insurance were made by patients with 2 to 3 MCC (45.5\% and 39.5\% respectively). At all ages, a greater proportion of visits by men with public rather than private insurance were made by patients with MCC. Visits made by women aged 45 or older with public rather than private insurance were more likely to be made by women with 2 or more chronic conditions.

Visits made by patients with no insurance were less likely to be made by patients with 2 or more chronic conditions (18.6\%) than were visits made by patients with public insurance (54.2\%). We saw this same pattern for all ages and for visits by both women and men.

Visits made by men with private insurance were more likely to be made by patients with 2 or 3 chronic conditions (28.7\%) than visits made by women with private insurance (20.7\%). This sex difference persisted for visits by those younger than 65 . We did not find a statistically significant sex difference by private insurance-for visits made by patients aged 65 or older or for visits made by patients with 4 or more chronic conditions.

Visits by men aged 18 to 44 with public insurance were more likely (19.0\%) than visits by women aged 18 to 44 ( $9.4 \%$ ) with public insurance to be made by patients with 2 or 3 chronic conditions. We did not find a significant sex difference by public insurance for visits made by patients aged 45 or older or for visits made by patients with 4 or more chronic conditions.

\section{Chronic condition dyads}

Hypertension, the most frequently occurring chronic condition, appeared in 21 of the 29 chronic conditions dyads listed in Table 4. The most frequent dyad was hypertension and hyperlipidemia, and its incidence increased with age for women. About $16.6 \%$ of visits by women aged 18 to 44 with 2 or more chronic conditions were made by patients having both hypertension and hyperlipidemia. This number increased for visits by women aged 45 to 64 (31.9\%) and 65 or older (40.6\%). More visits by adult men than women aged 18 to 64 with 2 or more chronic conditions were made by patients with both hypertension and hyperlipidemia. Diabetes with hypertension and diabetes with hyperlipidemia were frequent dyads, appearing in the top 5 dyads for all age groups for visits by both men and women. Hypertension and arthritis was a frequently occurring dyad for visits by both men and women aged 45 or older, and frequency increased with age. Unlike other dyads, visits by women were more likely than visits by men to be made by patients with hypertension and arthritis. 


\section{Chronic condition triads}

An estimated 179,518,000 physician office visits were made by patients with 3 or more chronic conditions. Hypertension, the most frequently occurring chronic condition, appeared in every listed triad (Table 5). Hyperlipidemia, the second most frequent chronic condition, was absent from only 5 of the listed triads.

The most prevalent chronic condition triad was hypertension, hyperlipidemia, and diabetes. This was the only triad for which we could produce reliable estimates for men and women aged 18 to 44 . More visits by men (48.9\%) than women (19.9\%) aged 18 to 44 with 3 or more chronic conditions and more visits by men (26.1\%) than women (19.3\%) aged 65 and older were made by patients with hypertension and hyperlipidemia and diabetes. There was not a significant sex difference for this triad for those aged 45 to 64 . Another common chronic condition triad was hypertension, hyperlipidemia, and arthritis, and more visits by women than men aged 45 to 64 and 65 or older were made by patients with this triad. Hypertension/diabetes/arthritis was also a common triad for visits by patients aged 45 or older. Visits by women aged 45 to $64(14.1 \%)$ were more likely than visits by men aged 45 to $64(7.7 \%)$ to be made by patients with this chronic condition triad. There was not a significant sex difference for this triad for those aged 65 or older. Hypertension/hyperlipidemia/depression was another common chronic condition triad for visits by women aged 45 or older and visits by men aged 45 to 64 . We found no difference by sex. Ischemic heart disease/hypertension/hyperlipidemia was a common triad for visits by men aged 45 or older.

\section{Number of medications ordered or prescribed at visits for patients with MCC}

Patients without MCC were more likely to make office visits during which no medications were ordered or prescribed (Figure). For 30\% of visits by patients with o or 1 chronic condition, no medications were prescribed. This number decreased to about $15 \%$ of visits made by patients with 2 to 3 chronic conditions and $11 \%$ of visits made by patients with 4 or more chronic conditions. Patients without MCC took fewer medications than did patients with 4 or more. We found a decreasing trend by number of medications for visits by patients without MCC, and an increasing trend for visits by patients with 4 or more chronic conditions. The trend was not significant for visits by patients with 2 or 3 MCC. More medications were ordered or prescribed during visits for patients with MCC. For example, at least 8 medications were ordered or prescribed for $4 \%$ of visits made by patients with o or 1 chronic condition, but this number climbed to $18 \%$ of visits made by patients with 2 or 3 chronic conditions and to $37 \%$ of visits made by patients with 4 or more chronic conditions.

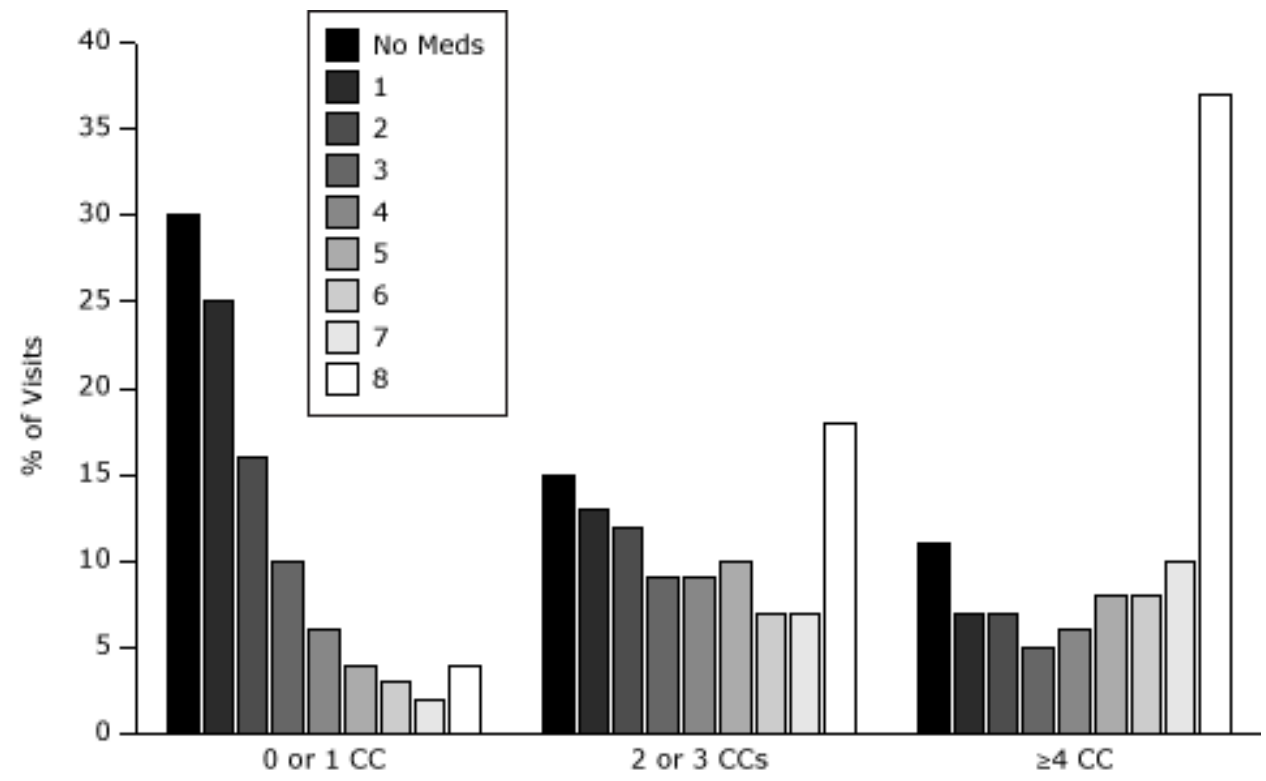

Figure. Physician office visits made by patients with or without chronic conditions, by number of medications ordered or prescribed. Shows percentage of office-based ambulatory care visits in which 0 through 8 or more medications were ordered or prescribed for each of 3 chronic condition groupings $(0$ or 1,2 or $3 \geq 4)$ (1). [A tabular version of this figure is also available.]

\section{Summary}

Our nationally representative study of office-based ambulatory care visits by adult patients with diagnoses of MCC contributes new information to the field. About $37.6 \%$ of adult visits were made by patients with MCC. Visits by patients with $\mathrm{MCC}$ were not evenly distributed by demographic characteristics. Visits by women comprised more than $60 \%$ of all visits. However, visits by men were more likely than visits by women to be made by patients with MCC. 
Visits by patients with MCC increased with age and were more likely to be made by patients with public insurance. Hypertension was the most common chronic condition in both dyads and triads. Hypertension-hyperlipidemia was the most common dyad, and these 2 conditions were the most common combination in the top triads, appearing in 17 of the 22 listed triads for this study. The most frequently occurring dyads and triads that included arthritis occurred more often at visits by women than men. However, frequent dyads and triads of other conditions were more likely at visits by men than women. More medications were ordered or prescribed during visits by patients with MCC than by patients without MCC. Visits by patients without MCC were more likely to have no or fewer medications ordered or prescribed than visits by patients with 4 or more chronic conditions.

Our study has limitations. Because the unit of analysis for NAMCS 2009 is an ambulatory care visit to a physician in the United States, the number of visits rather than number of people are measured, so it is possible for the same person to be counted multiple times. In addition, anyone who did not visit a doctor in 2009 was excluded from NAMCS 2009, including Medicare beneficiaries who did not visit a doctor. Thus, our results are not directly comparable with results presented in the Chronic Conditions Among Medicare Beneficiaries, Chart Book (4). According to the chart book, about $16 \%$ of all Medicare beneficiaries did not visit a doctor in 2009, representing about $33 \%$ of beneficiaries without MCC and about $9 \%$ of beneficiaries with MCC (4). The National Health Interview Survey (5) estimates that about $92 \%$ of US residents aged 65 or older have Medicare (5). NAMCS 2009 estimated that $79 \%$ of visits by patients aged 65 or older were made by patients with Medicare. NAMCS has check boxes for 13 chronic conditions, whereas the chart book tracks 15 chronic conditions (4); therefore, our results may undercount Medicare beneficiaries with MCC. Despite these differences, we found that visits by patients with MCC were more likely to be made by patients with public rather than private insurance.

As a nationally representative survey of office-based medical care, our study provides information about ambulatory medical care received by patients with MCC by demographic characteristics and identified the most frequently occurring dyads and triads of chronic conditions.

\section{Acknowledgments}

The authors received no financial support for the research described in this article.

\section{Author Information}

Corresponding Author: Jill Jacobsen Ashman, Centers for Disease Control and Prevention, National Center for Health Statistics, Division of Health Care Statistics, 3311 Toledo Rd, Room 3229, Hyattsville, MD 20782. Telephone: 301-4584439. E-mail: JAshman@cdc.gov.

Author Affiliation: Vladislav Beresovsky, Centers for Disease Control and Prevention, Hyattsville, Maryland.

\section{References}

1. National Center for Health Statistics. National Ambulatory Medical Care Survey micro-data file documentation, 2009. Hyattsville (MD): National Center for Health Statistics.

ftp://ftp.cdc.gov/pub/Health_Statistics/NCHS/Dataset_Documentation/NAMCS/doco9.pdf. Accessed February 11, 2013.

2. Parekh AK, Goodman RA, Gordon C, Koh HK. HHS Interagency Workgroup on Multiple Chronic Conditions. Managing multiple chronic conditions: a strategic framework for improving health outcomes and quality of life. Public Health Rep 2011;126(4):460-71. PubMed 图

3. National Ambulatory Medical Care Survey: 2009 Summary Tables, Table 21. http://www.cdc.gov/nchs/data/ahcd/namcs_summary/2009_namcs_web_tables.pdf. Accessed February 12, 2013.

4. Centers for Medicare \& Medicaid Services. Chronic conditions among Medicare beneficiaries, chart book. Baltimore (MD); 2011. http://www.cms.gov/Research-Statistics-Data-and-Systems/Statistics-Trends-andReports/Chronic-Conditions/Downloads/2011Chartbook.pdf. Accessed February 8, 2013.

5. National Health Interview Survey 2004. http://www.cdc.gov/nchs/data/hestat/impacto4/impact_tableso4.pdf\#3. Accessed February 12, 2013. 
Preventing Chronic Disease I Multiple Chronic Conditions Among US Adults Who Visite... Page 6 of 13

\section{Tables}

Table 1. Selected Demographics of Visits by Patients 18 or Older, National Ambulatory Medical Care Survey, 2009

\begin{tabular}{|c|c|c|}
\hline Selected Demographics & Weighted Number (SE), in 1000s & $\%$ (SE) \\
\hline All patients & $867,783(39,012)$ & 100 \\
\hline \multicolumn{3}{|l|}{ Race/ethnicity } \\
\hline Non-Hispanic white & $654,544(33,353)$ & $75.4(1.3)$ \\
\hline Non-Hispanic black & $90,797(6,779)$ & $10.5(0.6)$ \\
\hline Non-Hispanic othera & $35,273(5,469)$ & $4.1(0.6)$ \\
\hline Hispanic & $87,169(8,684)$ & $10.0(1.0)$ \\
\hline \multicolumn{3}{|l|}{ Age, y } \\
\hline $18-44$ & $267,057(12,331)$ & $30.8(0.8)$ \\
\hline $45-64$ & $320,375(16,670)$ & $36.9(0.7)$ \\
\hline$\geq 65$ & $280,351(15,021)$ & $32.3(0.8)$ \\
\hline \multicolumn{3}{|l|}{ Sex } \\
\hline Women & $535,675(24,422)$ & $61.7(0.7)$ \\
\hline Men & $332,108(16,311)$ & $38.3(0.7)$ \\
\hline \multicolumn{3}{|c|}{ Expected source of payment } \\
\hline Private insurance & $448,470(20,736)$ & $51.7(1.1)$ \\
\hline Public insuranceb & $328,782(19,232)$ & $37.9(1.1)$ \\
\hline Other insurancec & $53,237(5,461)$ & $6.1(0.6)$ \\
\hline No insuranced & $37,294(2,695)$ & $4.3(0.3)$ \\
\hline
\end{tabular}

Table 2. Physician Office Visits by Patients With Chronic Conditions by Sex, Age, and Race/Ethnicity, National Ambulatory Medical Care Survey, 2009

\begin{tabular}{|c|c|c|c|}
\hline $\begin{array}{l}\text { Sex, Age, } \\
\text { Race/Ethnicity }\end{array}$ & $\begin{array}{l}\text { 0-1 Chronic Conditions, \% } \\
\text { (SE) }\end{array}$ & $\begin{array}{l}\text { 2-3 Chronic Conditions, \% } \\
\text { (SE) }\end{array}$ & $\begin{array}{l}\geq 4 \text { Chronic Conditions, \% } \\
\text { (SE) }\end{array}$ \\
\hline \multicolumn{4}{|l|}{ Total } \\
\hline All $\geq 18 y$ & $62.5(1.1)$ & $29.2(0.9)$ & $8.4(0.5)$ \\
\hline Non-Hispanic white & $61.4(1.2)$ & $29.8(0.9)$ & $8.8(0.6)$ \\
\hline Non-Hispanic black & $62.6(2.1)$ & $30.3(1.7)$ & $7.1(0.9)$ \\
\hline Non-Hispanic othera & $71.9(4.5)$ & $22.3(3.8)$ & $5.8(1.3)$ \\
\hline Hispanic & $66.7(2.5)$ & $25.9(1.9)$ & $7.3(1.6)$ \\
\hline All 18-44 y & $89.7(0.7)$ & $9.3(0.6)$ & $1.1(0.2)$ \\
\hline Non-Hispanic white & $89.6(0.7)$ & $9.2(0.6)$ & $1.1(0.2)$ \\
\hline
\end{tabular}




\begin{tabular}{|c|c|c|c|}
\hline $\begin{array}{l}\text { Sex, Age, } \\
\text { Race/Ethnicity }\end{array}$ & $\begin{array}{l}\text { 0-1 Chronic Conditions, \% } \\
\text { (SE) }\end{array}$ & $\begin{array}{c}\text { 2-3 Chronic Conditions, \% } \\
\text { (SE) }\end{array}$ & $\begin{array}{c}\geq 4 \text { Chronic Conditions, \% } \\
\text { (SE) }\end{array}$ \\
\hline Non-Hispanic black & $87.3(2.2)$ & $11.6(2.0)$ & $-b$ \\
\hline Non-Hispanic othera & $92.1(2.2)$ & $7.6(2.2)$ & $-b$ \\
\hline Hispanic & $91.2(1.3)$ & $7.8(1.3)$ & $-b$ \\
\hline All 45-64 y & $60.7(1.1)$ & $32.4(0.9)$ & $7.0(0.5)$ \\
\hline Non-Hispanic white & $60.8(1.2)$ & $31.8(1.0)$ & $7.4(0.7)$ \\
\hline Non-Hispanic black & $54.5(2.3)$ & $39.7(2.1)$ & $5.8(0.8)$ \\
\hline Non-Hispanic othera & $73.3(5.7)$ & $22.0(4.9)$ & $-b$ \\
\hline Hispanic & $61.0(3.5)$ & $33.1(3.4)$ & $5.9(1.7)$ \\
\hline All $\geq 65 y$ & $38.6(1.3)$ & $44.4(1.2)$ & $16.9(1.0)$ \\
\hline Non-Hispanic white & $39.0(1.5)$ & $44.3(1.3)$ & $16.7(1.0)$ \\
\hline Non-Hispanic black & $37.0(3.4)$ & $44.5(3.1)$ & $18.5(2.3)$ \\
\hline Non-Hispanic othera & $45.0(6.1)$ & $41.0(5.5)$ & $14.0(3.3)$ \\
\hline Hispanic & $34.4(3.2)$ & $46.5(3.3)$ & $19.2(4.1)$ \\
\hline \multicolumn{4}{|c|}{ Women } \\
\hline All $\geq 18$ y & $65.0(1.1)$ & $27.0(0.9)$ & $8.0(0.5)$ \\
\hline Non-Hispanic white & $63.5(1.3)$ & $28.0(1.0)$ & $8.5(0.6)$ \\
\hline Non-Hispanic black & $65.4(2.5)$ & $27.4(2.0)$ & $7.1(1.3)$ \\
\hline Non-Hispanic othera & $75.3(3.9)$ & $19.2(3.3)$ & $5.5(1.5)$ \\
\hline Hispanic & $70.7(2.6)$ & $22.5(2.0)$ & $6.8(1.6)$ \\
\hline All $18-44 y$ & $91.0(0.6)$ & $8.2(0.6)$ & $0.8(0.2)$ \\
\hline Non-Hispanic white & $90.2(0.7)$ & $8.8(0.6)$ & $1.0(0.3)$ \\
\hline Non-Hispanic black & $90.8(1.7)$ & $8.6(1.7)$ & $-b$ \\
\hline Non-Hispanic othera & $94.3(2.2)$ & $5.7(2.4)^{b}$ & $-b$ \\
\hline Hispanic & $93.6(1.3)$ & $6.0(1.3)$ & $-b$ \\
\hline All 45-64 y & $62.9(1.2)$ & $30.1(1.0)$ & $7.1(0.6)$ \\
\hline Non-Hispanic white & $62.8(1.2)$ & $30.0(1.1)$ & $7.2(0.7)$ \\
\hline Non-Hispanic black & $56.4(2.5)$ & $37.4(2.5)$ & $6.2(1.2)$ \\
\hline Non-Hispanic othera & $72.5(6.1)$ & $20.7(4.8)$ & $-b$ \\
\hline Hispanic & $67.1(3.5)$ & $26.2(2.9)$ & $6.7(2.0)$ \\
\hline All $\geq 65 y$ & $37.7(1.6)$ & $44.9(1.4)$ & $17.4(1.0)$ \\
\hline Non-Hispanic white & $38.6(1.8)$ & $44.4(1.5)$ & $17.0(1.2)$ \\
\hline Non-Hispanic black & $32.7(3.8)$ & $46.8(3.7)$ & $20.5(3.4)$ \\
\hline Non-Hispanic othera & $45.5(5.8)$ & $41.2(5.5)$ & $-b$ \\
\hline Hispanic & $31.6(3.5)$ & $49.6(4.2)$ & $18.8(4.4)$ \\
\hline \multicolumn{4}{|c|}{ Men } \\
\hline All $\geq 18 y$ & $58.4(1.3)$ & $32.6(1.1)$ & $9.0(0.7)$ \\
\hline Non-Hispanic white & $58.0(1.3)$ & $32.6(1.1)$ & $9.4(0.8)$ \\
\hline Non-Hispanic black & $57.1(3.1)$ & $35.8(2.8)$ & $7.1(1.7)$ \\
\hline Non-Hispanic othera & $66.5(6.7)$ & $27.2(5.7)$ & $-b$ \\
\hline
\end{tabular}




\begin{tabular}{|c|c|c|c|}
\hline $\begin{array}{l}\text { Sex, Age, } \\
\text { Race/Ethnicity }\end{array}$ & $\begin{array}{c}\text { 0-1 Chronic Conditions, \% } \\
\text { (SE) }\end{array}$ & $\begin{array}{c}\text { 2-3 Chronic Conditions, \% } \\
\text { (SE) }\end{array}$ & $\begin{array}{c}\geq 4 \text { Chronic Conditions, \% } \\
\text { (SE) }\end{array}$ \\
\hline Hispanic & $59.4(3.2)$ & $32.2(2.7)$ & $8.4(1.9)$ \\
\hline All 18-44 y & $86.6(1.3)$ & $11.6(1.1)$ & $1.8(0.4)$ \\
\hline Non-Hispanic white & $88.4(1.3)$ & $10.1(1.0)$ & $-b$ \\
\hline Non-Hispanic black & $77.0(6.9)$ & $20.1(5.5)$ & $-b$ \\
\hline Non-Hispanic othera & $85.5(4.9)$ & $-b$ & $-b$ \\
\hline Hispanic & $85.4(2.3)$ & $12.2(2.2)$ & $-b$ \\
\hline All 45-64 y & $57.5(1.5)$ & $35.6(1.4)$ & $6.8(0.7)$ \\
\hline Non-Hispanic white & $58.0(1.6)$ & $34.5(1.5)$ & $7.5(0.9)$ \\
\hline Non-Hispanic black & $51.8(4.6)$ & $43.0(4.4)$ & $5.2(1.5)$ \\
\hline Non-Hispanic othera & $74.4(6.5)$ & $23.6(6.1)$ & $-b$ \\
\hline Hispanic & $51.5(5.2)$ & $43.9(5.3)$ & $-b$ \\
\hline All $\geq 65 y$ & $40.0(1.6)$ & $43.7(1.5)$ & $16.3(1.4)$ \\
\hline Non-Hispanic white & $39.5(1.7)$ & $44.3(1.7)$ & $16.2(1.6)$ \\
\hline Non-Hispanic black & $44.5(5.8)$ & $40.4(6.1)$ & $15.1(4.3)$ \\
\hline Non-Hispanic othera & $44.4(8.8)$ & $40.7(8.3)$ & $-b$ \\
\hline Hispanic & $38.4(5.1)$ & 41.9 (4.4) & $19.7(4.5)$ \\
\hline
\end{tabular}

Abbreviation: SE, standard error.

a Non-Hispanic other includes Asians, Native Hawaiian/Pacific Islanders, American Indian/Alaska Natives, and persons of mixed race.

b Estimate does not meet standards of reliability or precision.

Table 3. Physician Office Visits by Patients With Chronic Conditions by Sex, Age, and Expected Source of Payment, National Ambulatory Medical Care Survey, 2009

\begin{tabular}{|c|c|c|c|}
\hline $\begin{array}{l}\text { Sex, Age, Expected Source } \\
\text { of Payment }\end{array}$ & $\begin{array}{r}0-1 \text { Chronic Conditions, } \\
\%(\mathrm{SE})\end{array}$ & $\begin{array}{r}\text { 2-3 Chronic Conditions, } \\
\%(\mathrm{SE})\end{array}$ & $\begin{array}{r}\geq 4 \text { Chronic Conditions, } \\
\% \text { (SE) }\end{array}$ \\
\hline \multicolumn{4}{|c|}{ Total } \\
\hline \multicolumn{4}{|l|}{ All $\geq 18 y$} \\
\hline All sources & $62.5(1.1)$ & $29.2(0.9)$ & $8.4(0.5)$ \\
\hline Private insurance & $71.6(1.0$ & $23.7(0.9)$ & $4.7(0.4)$ \\
\hline Public insurance ${ }^{a}$ & $45.8(1.6)$ & $39.5(1.3)$ & $14.7(0.9)$ \\
\hline Other insuranceb & $75.1(2.6)$ & $20.2(2.1)$ & $4.7(0.8)$ \\
\hline No insurancec & $81.4(2.0)$ & $16.0(1.7)$ & $2.6(0.6)$ \\
\hline \multicolumn{4}{|l|}{$18-44 y$} \\
\hline All sources & $89.7(0.7)$ & $9.3(0.6)$ & $1.1(0.2)$ \\
\hline Private insurance & $90.1(0.8)$ & $9.2(0.7)$ & $-d$ \\
\hline Public insurance a & $85.4(1.6)$ & $11.6(1.3)$ & $3.0(0.8)$ \\
\hline Other insurance $b$ & $93.4(1.6)$ & $6.3(1.6)$ & $-d$ \\
\hline No insurancec & $92.5(1.6)$ & $7.0(1.5)$ & $-d$ \\
\hline \multicolumn{4}{|l|}{$45-64 y$} \\
\hline
\end{tabular}




\begin{tabular}{|c|c|c|c|}
\hline $\begin{array}{l}\text { Sex, Age, Expected Source } \\
\text { of Payment }\end{array}$ & $\begin{array}{r}\text { 0-1 Chronic Conditions, } \\
\%(\mathrm{SE})\end{array}$ & $\begin{array}{r}\text { 2-3 Chronic Conditions, } \\
\%(\mathrm{SE})\end{array}$ & $\begin{array}{r}\geq 4 \text { Chronic Conditions, } \\
\% \text { (SE) }\end{array}$ \\
\hline All sources & $60.7(1.1)$ & $32.4(0.9)$ & $7.0(0.5)$ \\
\hline Private insurance & $63.0(1.1)$ & $31.5(1.1)$ & $5.6(0.5)$ \\
\hline Public insurance a & $45.4(2.8)$ & $40.6(2.1)$ & $14.1(1.5)$ \\
\hline Other insurance $b$ & $67.2(3.0)$ & $26.6(2.3)$ & $6.2(1.2)$ \\
\hline No insurance $c$ & $69.2(3.3)$ & $26.5(2.8)$ & $4.3(1.1)$ \\
\hline \multicolumn{4}{|l|}{$\geq 65 y$} \\
\hline All sources & $38.6(1.3)$ & $44.4(1.2)$ & $16.9(1.0)$ \\
\hline Private insurance & $45.3(2.3)$ & $39.5(1.8)$ & $15.2(1.6)$ \\
\hline Public insurance a & $37.1(1.4)$ & $45.5(1.3)$ & $17.4(1.1)$ \\
\hline Other insurance $b$ & $32.6(5.3)$ & $51.3(5.7)$ & $16.1(3.9)$ \\
\hline No insurance c & $75.0(6.3)$ & $-d$ & $-d$ \\
\hline \multicolumn{4}{|c|}{ Women } \\
\hline \multicolumn{4}{|l|}{ All $\geq 18 y$} \\
\hline All sources & $65.0(1.1)$ & $27.0(0.9)$ & $8.0(0.5)$ \\
\hline Private insurance & $75.1(1.0)$ & $20.7(0.8)$ & $4.3(0.4)$ \\
\hline Public insurancea & $47.4(1.9)$ & $38.2(1.5)$ & $14.3(1.0)$ \\
\hline Other insuranceb & $77.8(2.5)$ & $17.9(2.1)$ & $4.5(0.8)$ \\
\hline No insurancec & $82.0(2.2)$ & $16.0(2.1)$ & $2.0(0.5)$ \\
\hline \multicolumn{4}{|l|}{$18-44 y$} \\
\hline All sources & $91.0(0.6)$ & $8.2(0.5)$ & $0.8(0.2)$ \\
\hline Private insurance & $91.3(0.7)$ & $8.3(0.7)$ & $-d$ \\
\hline Public insurance a & $88.1(1.6)$ & $9.4(1.3)$ & $-d$ \\
\hline Other insuranceb & $94.0(1.4)$ & $5.5(1.3)$ & $-d$ \\
\hline No insurancec & $92.9(1.8)$ & $7.1(1.8)$ & $-d$ \\
\hline \multicolumn{4}{|l|}{$45-64 y$} \\
\hline All sources & $62.9(1.2)$ & $30.1(1.0)$ & $7.0(0.6)$ \\
\hline Private insurance & $66.1(1.2)$ & $28.5(1.2)$ & $5.4(0.6)$ \\
\hline Public insurance ${ }^{a}$ & $45.9(2.8)$ & $39.2(2.3)$ & $14.9(2.0)$ \\
\hline Other insuranceb & $67.6(3.5)$ & $25.7(3.1)$ & $6.7(1.7)$ \\
\hline No insurance $c$ & $69.4(3.5)$ & $26.6(3.3)$ & $3.9(1.1)$ \\
\hline \multicolumn{4}{|l|}{$\geq 65 y$} \\
\hline All sources & $37.7(1.6)$ & $44.9(1.4)$ & $17.4(1.0)$ \\
\hline Private insurance & 44.9 (3.4) & $38.1(2.4)$ & $16.9(2.2)$ \\
\hline Public insurance ${ }^{a}$ & $36.0(1.7)$ & $46.3(1.5)$ & $17.6(1.2)$ \\
\hline Other insurance ${ }^{b}$ & $35.3(6.5)$ & $50.7(6.4)$ & $-d$ \\
\hline No insurancec & $79.2(6.3)$ & $-d$ & $-d$ \\
\hline \multicolumn{4}{|c|}{ Men } \\
\hline \multicolumn{4}{|l|}{ All $\geq 18 y$} \\
\hline All sources & $58.4(1.3)$ & $32.6(1.1)$ & $9.0(0.7)$ \\
\hline
\end{tabular}




\begin{tabular}{|c|c|c|c|}
\hline $\begin{array}{l}\text { Sex, Age, Expected Source } \\
\text { of Payment }\end{array}$ & $\begin{array}{r}\text { 0-1 Chronic Conditions, } \\
\%(\mathrm{SE})\end{array}$ & $\begin{array}{r}\text { 2-3 Chronic Conditions, } \\
\%(\mathrm{SE})\end{array}$ & $\begin{array}{r}\geq 4 \text { Chronic Conditions, } \\
\% \text { (SE) }\end{array}$ \\
\hline Private insurance & $65.9(1.4)$ & $28.7(1.2)$ & $5.4(0.6)$ \\
\hline Public insurance a & $43.1(1.7)$ & $41.7(1.6)$ & $15.2(1.3)$ \\
\hline Other insurance $b$ & $71.8(3.4)$ & $23.1(3.0)$ & $5.1(1.4)$ \\
\hline No insurance $c$ & $80.4(2.5)$ & $16.1(2.1)$ & $3.5(1.2)$ \\
\hline \multicolumn{4}{|l|}{$18-44 y$} \\
\hline All sources & $86.6(1.3)$ & $11.6(1.1)$ & $1.8(0.4)$ \\
\hline Private insurance & $87.2(1.4)$ & $11.3(1.2)$ & $-d$ \\
\hline Public insurance a & $76.3(3.9)$ & $19.0(3.0)$ & $-d$ \\
\hline Other insurance $b$ & $92.4(2.7)$ & $7.6(2.7)$ & $-d$ \\
\hline No insurance c & $92.0(2.0)$ & $6.9(1.9)$ & $-d$ \\
\hline \multicolumn{4}{|l|}{$45-64 y$} \\
\hline All sources & $57.5(1.5)$ & $35.6(1.4)$ & $6.8(0.7)$ \\
\hline Private insurance & $58.6(1.6)$ & $35.7(1.6)$ & $5.8(0.7)$ \\
\hline Public insurancea & 44.5 (3.9) & 42.7 (3.9) & $12.8(2.0)$ \\
\hline Other insuranceb & $66.8(3.5)$ & $27.5(3.1)$ & $-d$ \\
\hline No insurancec & $68.8(4.6)$ & $26.4(4.1)$ & $-d$ \\
\hline \multicolumn{4}{|l|}{$\geq 65 y$} \\
\hline All sources & $40.0(1.6)$ & $43.7(1.5)$ & $16.3(1.4)$ \\
\hline Private insurance & $45.9(2.7)$ & $41.1(3.1)$ & $13.0(1.8)$ \\
\hline Public insurance ${ }^{a}$ & $38.5(1.7)$ & $44.3(1.5)$ & $17.1(1.5)$ \\
\hline Other insurance & $30.4(6.6)$ & $51.9(7.6)$ & $-d$ \\
\hline No insurancec & $71.2(11.5)$ & $-d$ & $-d$ \\
\hline
\end{tabular}

Abbreviation: SE, standard error.

a Public insurance includes Medicare and Medicaid.

b Other insurance includes Workers' Compensation, other insurance, and unknown ( $2.4 \%$ of visits).

c No insurance includes self-pay, no charge, and charity.

d Estimate does not meet standards of reliability or precision.

Table 4. Physician Office Visits by Patients With the 5 Most Prevalent Dyads of Chronic Conditions, by Sex and Age, National Ambulatory Medical Care Survey, 2009

\begin{tabular}{|l|r|}
\hline Sex, Age, and Dyads & \multicolumn{1}{|c|}{ Women } \\
\hline \multicolumn{2}{|c|}{ Chronic Conditionsa, \% (SE) } \\
\hline 18-44 y & $18.1(2.1)$ \\
\hline Hypertension/diabetes & $16.6(2.0)$ \\
\hline Hypertension/hyperlipidemia & $15.6(2.1)$ \\
\hline Depression/asthma & $14.9(2.0)$ \\
\hline Hypertension/depression & $11.5(1.8)$ \\
\hline Hyperlipidemia/diabetes & \\
\hline 45-64 y & \\
\hline
\end{tabular}




\begin{tabular}{|c|c|}
\hline Sex, Age, and Dyads & $\geq 2$ Chronic Conditionsa, $\%$ (SE) \\
\hline Hypertension/hyperlipidemia & $31.9(1.6)$ \\
\hline Hypertension/diabetes & $26.1(1.5)$ \\
\hline Hypertension/arthritis & $21.3(1.4)$ \\
\hline Hyperlipidemia/diabetes & $17.4(1.3)$ \\
\hline Hypertension/depression & $15.1(1.2)$ \\
\hline \multicolumn{2}{|l|}{$\geq 65 y$} \\
\hline Hypertension/hyperlipidemia & $40.6(1.8)$ \\
\hline Hypertension/arthritis & $28.6(2.1)$ \\
\hline Hypertension/diabetes & $24.0(1.4)$ \\
\hline Hyperlipidemia/arthritis & $16.6(1.6)$ \\
\hline Hyperlipidemia/diabetes & $14.7(1.2)$ \\
\hline \multicolumn{2}{|c|}{ Men } \\
\hline \multicolumn{2}{|l|}{$18-44 y^{b}$} \\
\hline Hypertension/hyperlipidemia & $32.7(3.8)$ \\
\hline Hypertension/diabetes & $27.5(3.4)$ \\
\hline Hyperlipidemia/diabetes & $22.7(3.0)$ \\
\hline Hypertension/depression & $15.2(2.5)$ \\
\hline \multicolumn{2}{|l|}{$45-64 y$} \\
\hline Hypertension/hyperlipidemia & $42.2(2.1)$ \\
\hline Hypertension/diabetes & $27.6(1.8)$ \\
\hline Hyperlipidemia/diabetes & $20.3(1.9)$ \\
\hline Hypertension/arthritis & $15.2(1.3)$ \\
\hline Hypertension/depression & $10.3(1.4)$ \\
\hline \multicolumn{2}{|l|}{$\geq 65 \mathrm{y}$} \\
\hline Hypertension/hyperlipidemia & $43.6(1.8)$ \\
\hline Hypertension/diabetes & $29.0(1.4)$ \\
\hline Hypertension/arthritis & $19.4(1.6)$ \\
\hline Hyperlipidemia/diabetes & $19.1(1.3)$ \\
\hline Ischemic heart disease/hypertension & $16.3(1.2)$ \\
\hline
\end{tabular}

Abbreviation: SE, standard error.

a The denominator includes all visits by patients with 2 or more CC, (N=337,100,000 visits). The percentage of visits for each age group does not equal $100 \%$ because patients may be included in multiple dyads, and data for only the 5 most frequent dyads for each age group are displayed.

b The remaining most frequent dyad estimate for visits by men aged 18-44 y does not meet standards of reliability or precision.

Table 5. Physician Office Visits by Patients With the 5 Most Prevalent Triads of Chronic Conditions, by Sex and Age, National Ambulatory Medical Care Survey, 2009 


\begin{tabular}{|c|c|}
\hline Sex, Age, Triad & $\geq 3$ Chronic Conditionsa, $\%$ (SE) a \\
\hline \multicolumn{2}{|l|}{$18-44 y^{b}$} \\
\hline Hypertension/hyperlipidemia/diabetes & $19.9(5.0)$ \\
\hline \multicolumn{2}{|l|}{$45-64 y$} \\
\hline Hypertension/hyperlipidemia/diabetes & $27.4(2.5)$ \\
\hline Hypertension/hyperlipidemia/arthritis & $17.5(2.1)$ \\
\hline Hypertension/diabetes/arthritis & $14.1(2.1)$ \\
\hline Hypertension/hyperlipidemia/depression & $12.2(1.4)$ \\
\hline Hypertension/depression/arthritis & $10.8(1.2)$ \\
\hline \multicolumn{2}{|l|}{$\geq 65 y$} \\
\hline Hypertension/hyperlipidemia/arthritis & $21.8(2.2)$ \\
\hline Hypertension/hyperlipidemia/diabetes & $19.3(1.7)$ \\
\hline Osteoporosis/hypertension/hyperlipidemia & $11.3(1.3)$ \\
\hline Hypertension/diabetes/arthritis & $11.0(1.1)$ \\
\hline Hypertension/hyperlipidemia/depression & $10.7(1.1)$ \\
\hline \multicolumn{2}{|c|}{ Men } \\
\hline \multicolumn{2}{|l|}{$18-44 y^{b}$} \\
\hline Hypertension/hyperlipidemia/diabetes & $48.9(6.7)$ \\
\hline \multicolumn{2}{|l|}{$45-64 y$} \\
\hline Hypertension/hyperlipidemia/diabetes & $31.5(2.8)$ \\
\hline Ischemic heart disease/hypertension/hyperlipidemia & $14.1(1.6)$ \\
\hline Hypertension/hyperlipidemia/depression & $10.8(1.8)$ \\
\hline Hypertension/hyperlipidemia/arthritis & $9.4(1.4)$ \\
\hline Hypertension/diabetes/arthritis & $7.7(1.3)$ \\
\hline \multicolumn{2}{|l|}{$\geq 65 y$} \\
\hline Hypertension/hyperlipidemia/diabetes & $26.1(2.0)$ \\
\hline Ischemic heart disease/hypertension/hyperlipidemia & $17.6(1.8)$ \\
\hline Hypertension/hyperlipidemia/arthritis & $15.0(1.9)$ \\
\hline Hypertension/diabetes/arthritis & $9.9(1.3)$ \\
\hline Hypertension/hyperlipidemia/cancer & $9.3(1.3)$ \\
\hline
\end{tabular}

Abbreviation: SE, standard error.

a The denominator includes all visits by patients with 3 or more chronic conditions, $(N=179,518,000$ visits $)$. The percentage of visits for each age group does not equal $100 \%$ because patients may be included in multiple triads, and data for only the 5 most frequent triads for each age group are displayed.

b The remaining most frequent triad estimates for visits by patients aged 18-44 do not meet standards of reliability or precision.

The opinions expressed by authors contributing to this journal do not necessarily reflect the opinions of the U.S. Department of Health and Human Services, the Public Health Service, the Centers for Disease Control and Prevention, or the authors' affiliated institutions. 
Preventing Chronic Disease I Multiple Chronic Conditions Among US Adults Who Vis... Page 13 of 13

bibliographic management applications such as EndNote $\$$, Reference Manager is available at each application's web site.

For Questions About This Article Contact pcdeditor@cdc.gov

Page last reviewed: April 25, 2013

Page last updated: April 25, 2013

Content source: National Center for Chronic Disease Prevention and Health Promotion

Centers for Disease Control and Prevention 1600 Clifton Rd. Atlanta, GA 30333, USA

800-CDC-INFO (800-232-4636) TTY: (888) 232-6348 - Contact CDC-INFO 